\title{
Career Plans of Novice University Teachers: The Research Perspective
}

\author{
Adriana Wiegerová ${ }^{*}$
}

DOI: $10.1515 /$ atd-2017-0001

Received: February 8, 2017; received in revised form: March 6, 2017; accepted: March 7, 2017

\begin{abstract}
:
Introduction: The career trajectories of young university teachers have been a relatively frequent research target in North American and Western European countries but an entirely neglected topic of the Czech and Slovak educational research. This paper's ambition is to narrow the gap. The research goal is to describe one aspect of career advancement of young university teachers - their professional plans after their entry to an academic position at a university after completion of their doctoral studies.
\end{abstract}

Methods: This qualitative investigation was concentrated on a sample of ten young university teachers currently employed in Czech universities. The data were gathered through in-depth interviews, sound recordings were converted to written transcripts, and then open- and category coded.

Results: The findings show how the young teachers adapted to the workplace environment, how they struggled with the double roles in academia, i.e., an instructor and a researcher, and which personal decisions they made for the next years in employment. I was revealed how the desire to attain assistant professorship overwhelmed their professional, occupational and personal decisions.

Limitations: As concerns the limitation of the findings, the qualitative investigation went deeply into the thinking and decision making of the study participants but was unable to draft wide generalisations.

Key words: professional career, occupational career, teacher, researcher, postdoc.

Adriana Wiegerová, Faculty of Humanities, University of Tomas Bata in Zlín, Zlín, Czech Republic; wiegerova@fhs.utb.cz 


\section{Acta Technologica Dubnicae \\ volume 7, 2017, issue 1}

\section{Introduction}

A career is defined as a developmental sequence that takes place during a life span. Its course can be either ascending or descending, it can comprise growth, stagnation or decline. A career is frequently conceptualized as an individual's professional and occupational trajectory.

A professional career is a developmental sequence in an individual's profession. It should be distinguished from the occupational career, as that refers to a broader concept. The professional career is an on-going process of developing experience in a profession, and it may evolve within several organizations in which an individual is employed during his/her lifetime. This concept also emphasizes the distinctive nature of a profession and its autonomy, as manifested by a special mandate, which has its own ethical codes and norms. These are the bases of the functioning of the professional community. The professional career is linked to experiences. It is a route which enables the understanding of one's behaviour and actions in professional life.

There are significant differences in valuing professional careers when we compare genders. As Weisgram, Bigler and Liben (2010) proved, some professions are traditionally characterized as feminine and others as masculine. The respondents labelled occupations with regards to money, power, family, and altruism. Results revealed gender differences in occupational values and interests. Furthermore, participants' values predicated their own interests in masculine and feminine professions. Importantly, this rating was proved across all age groups (adults, adolescents and children).

An occupational career is a developmental sequence in one's occupations. The selection criterion of a particular occupation is the salary or other benefits, such as power or authority, as well as time available to share with family and for one's leisure time activities. The occupational career comprises not only an occupational position; it also includes "work ownership", employment and its execution. An occupation is regulated by workplace rules as well as by general occupational norms, such as the labour code.

The professional career is influenced by values and personal constructs, which, in turn, shape one's self-concept. Values are relatively stable personal qualities that considerably affect one's attitudes towards other people, situations and objects. Personal values serve as standards for assessing one's own behaviour and the behaviour of others.

An employee's professional career planning in an organisation is a process aimed at securing a required occupational position in a profession. In this 


\section{Acta Technologica Dubnicae \\ volume 7, 2017, issue 1}

planning, professional and occupational careers intersect. An individual delineates his/her growth and progression in an organisation, based on the needs of this organisation. An organisation plans the professional careers of its employees based on the employees' potentials, attainments, and the organisation's preferences. A well-functioning career planning system encourages employees to take more responsibility for their own development, including the development of the skills viewed as critical for the institution (Milkovich \& Boudreau, 1993).

The employees' professional career planning in an organisation must take into consideration the professional orientation of each employee. This orientation is determined by the employee's abilities, motivation, and value preferences.

Professional career planning is a subset of professional career management. The organisation selects employees, evaluates and directs them in order to achieve the best possible performance of the institution. This is based on a management policy designed to maximize the potentials of an organisation. The policy includes whether an institution concentrates on internal employee development or whether it hires them externally. The policy also includes the decision whether to train narrowly-specialized or broadly-skilled workers and also what strategies to adopt if careers stagnate.

Besides professional career planning, which is provided by an institution, there is also an individual's professional planning, which is the responsibility of an individual. An individual's career plans should be established after careful selfassessment of abilities, knowledge, attitudes, values and experiences. This planning is more efficient if an individual can receive advice from a more experienced co-worker who can judge the adequacy of the individual's professional career aspirations. The career plan plays an important role in setting of an individual's career goals. It is a result of self-assessment and judgment of goal-attainment conditions.

Educational research has accumulated rich data about the studies and lives of doctoral students (Davis, 2003; Gardner, 2007; McAlpine, Jazvac-Martek, \& Hopwood, 2009; Turner \& McAlpine, 2011; Jaraim \& Kahl, 2012; Neusar, Charvát et al., 2012; Vekkaila, Pyhältö, \& Lonka, 2013). A wealth of information has also been collected about postdoctoral years (Melin, 2005; Mareš, 2013, Åkerlind, 2007, 2008). However, data about the professional paths of university teachers after completion of their doctoral studies are scarce. Some findings were published by Šed'ová et al. (2016), but they concentrated primarily on the quality of teaching and self-concept of novice teachers at a particular Czech university. 


\section{Acta Technologica Dubnicae \\ volume 7,2017 , issue 1}

This study provides a deeper examination of the occupational and professional careers of novice university teachers. The data illustrate what they experienced after being employed at a university, how they work within the system and how they perceive the influences and contexts that affected them in the university environment and beyond it.

\section{Methodology}

The aim of this study is to understand the process during which university graduates become university teachers.

This broad aim is subdivided into two specific aims:

1. To describe the developmental phases in occupational and academic careers of novice university teachers.

2. To describe the external and internal factors that determined the professional growth of novice university teachers.

This study concentrates on participants who completed a doctorate and subsequently became teachers at a university. The occupational and professional careers of some of them were not straightforward, but included digressions, critical moments, situations and events that dramatized their careers and brought strong professional and personal challenges and stimuli. My intention was to capture and describe these career situations and moments - as they were reconstructed in the participants' accounts.

The participants were acting and developing in concrete occupational and professional environments. In the beginning, my intention was to concentrate only on the personalities of the participants, however, during the investigation in agreement with the canons of qualitative inquiries - it appeared fruitful to broaden the scope of investigation and describe how the occupational and professional environments function, as viewed by the study participants. Therefore, another aim came to present the university environment as a domain in which occupational and professional carriers intersect.

The study aims are limited by the field of investigation. The exploration of becoming a university teacher was restricted to graduates in pedagogy. Therefore, their processes and determinants are bound by this discipline, though some data and their interpretations may extrapolate to other domains, at least by suggesting new questions for future investigations.

The research method in this study was an in-depth interview. In the preparatory phase, the content frame of the interview was constituted. 


\section{Acta Technologica Dubnicae \\ volume 7, 2017, issue 1}

The frame consisted of following topics:

- reasons to study in a doctoral programme

- doing coursework

- conducting dissertation research

- writing the dissertation

- views of university teacher responsibilities

- identification with the position of a university teacher

- identification with the position of a researcher

- views of the subsequent phases of the professional career

The participants provided informed consent. The purpose of the study and the circumstances were explained to them, including how their anonymity will be protected by the researcher. The place and the time of interview were negotiated. The interview consisted of a set of questions generated from the thematic domains. Many additional questions emerged during the interview. The first few interviews convinced me of the relevance of the thematic domains. Gradually, the questions became clearer and more aim-directed. My strategy was to let the interviewee talk continuously, as interruption-free as possible.

Only two identical questions were posed to all participants, the first and the last. The intention of the first question was to involve the participant in the interview. The question was, "What do you remember about your doctoral studies?" It elicited recollections and thus served as an efficient stimulus. The last question, "What will you recall tonight about our meeting?" aimed at participant's selfreflection.

A specific feature of the interview was that the participants themselves are familiar with empirical research, so they could follow critically my management of the interview. They observed various aspects of my verbal and nonverbal communication and probably assessed them. Being aware of this "participatory monitoring" brought a certain burden to my interview conduction.

Another specific feature was that the participants themselves posed questions to me. This also may be attributed to participants' experiences with the research. For instance, they frequently asked a question such as "How was this in your case?" This can be interpreted as testing the researcher and as an effort to gain a stronger position in the conversation. The participants sometimes posed questions because they were unable to answer my questions. Interestingly, such questions were only asked by women.

The interviews generally took place at the participants' "home universities" and in their offices, to make them feel at ease. There were two exceptions: two male 


\section{Acta Technologica Dubnicae \\ volume 7, 2017, issue 1}

participants agreed to be interviewed outside of their workplaces, but still at a university, a relatively familiar environment. The duration of the interviews was dictated by participants' time constraints, albeit with a minimum requirement of one hour.

Each interview was recorded on two voice recorders. This was to ensure that the interview would not be lost even if one of the recorders failed to record. Transcripts were made from both recordings by two assistants and the two versions of the transcripts were compared for accuracy. Discrepancies were resolved in a discussion. As a result, a single transcript was made from the two.

The analysis was based on a recursive reading of transcripts, through which I gradually immersed myself into the thinking and opinions of the participants and created a global view of them attempting to understand the interview as a compact whole (Pope et al., 2000). I made frequent interpretative memos, highlighted important segments and looked for relationships among them.

In the analysis, I used the principle of induction, the advantage of which is the potential of revealing new perspectives on the investigated raw data. In this way, new categories were created and relationships among them traced.

While reading and analysing the transcripts, firstly the sensitive segments were identified, i.e. those pieces of text that seemed most relevant. These were then attributed labels, or codes. The segments varied in respect to length, however, none was a single word, rather, they were chains of several words. For instance, codes were "rules of supervisor-doctoral student communication," "collision of two jobs," or "desire to become a university teacher". After having identified a certain amount of codes, they were systematized and grouped according to the meaning they carried, and then were hierarchically ordered.

For instance:

Phases of the doctoral study

Motivation for enrolling in the doctoral programme

Acceptance of the role of a doctoral student

Writing the dissertation

Integration into the professional community

Theory construction is an important component of qualitative enquiry. Theories were being developed continuously in the data analysis and were accompanied by drawing diagrams of categories. These diagrams underwent changes in every phase of the analysis. 


\section{Acta Technologica Dubnicae \\ volume 7, 2017, issue 1}

\section{Results}

In this article, I concentrate exclusively on the description of the professional plans of young university teachers after their entry to an academic position at a university after completion of their doctoral studies. Earlier stages of their academic careers, i.e. the period of their $\mathrm{PhD}$ studies, will be the topic of other publications.

In the course of their $\mathrm{PhD}$ studies, the participants viewed the university environment through a student perspective. In addition to attending lectures and seminars, they visited offices of supervisors, teachers and university administrators. Their acquaintance with the university environment affected their occupational and academic career plans and influenced their personal constructs.

Workplace experiences are closely associated with workplace adaptation, in this case with adaptation to the university. Adaptation is supported by one's representation of the reality, i.e. by the way in which shared beliefs of a group of people develop and are transferred to others (Hayes, 1998). In this case, $\mathrm{PhD}$ graduates accepted the social representations mediated by university employees. Social representation is a traditional folk wisdom spread among institutional workers. Occupational motivation plays a vital role in the manner of acceptance of social representations.

\subsection{The Goal-Associate Professorship}

None of the participants doubted their decision to take a university job. They all found this workplace enticing and felt they belonged in it. The subsequent stages of their professional careers were subordinated to the goal of having a job at a university, or rather, to sustaining the job there. Thus, the participants realized that their professional life did not culminate in earning a $\mathrm{PhD}$ degree. On the contrary, they learned that this degree created an opportunity to achieve the next goal - obtaining an associate professorship.

If I sum it up I would like to be an associate professor, and I hope I shall be one day. I want to extend my contract with the university, and I know how important this degree is. It increases my chance that they will let me work here. (F2)

Because I want to remain at the university, there is no other option than to struggle for an associate professorship. (F1)

Universities push teachers to produce "normed" achievements and to follow prescribed career routes. Publications and higher degrees increase the credibility of a university. Thus, teachers are directed by departments to set out on the track of earning an associate professorship within five to ten years after earning a $\mathrm{PhD}$. 


\section{Acta Technologica Dubnicae \\ volume 7,2017 , issue 1}

At our faculty, career growth is closely followed. Simply, we receive deadlines from administrators for reaching the next career stage. I am aware that I must be an associate professor. However, one has to have time to mature. Unfortunately, it seems that a university is a kind of a factory for producing associate professors, and I do not think some individuals are mature enough for it. (M3)

University pressures, as described by the participant, are understandable. A university needs "recognized publications" by employees in order to qualify for programme accreditation. Publications and accredited programmes, in turn, are criteria for the government subsidisation of a university, including the subsidy for number of students. However, the professional and personal maturation of teachers varies. The number of students who earn a $\mathrm{PhD}$ at the age of 25-30 increases every year. In the past, it was usual that a university teacher first earned a PaedDr degree (lower level doctorate) and only then enrolled in a $\mathrm{PhD}$ programme. In principle, a $\mathrm{PhD}$ was earned ten years after receiving a master's degree and a PhD graduate was 30-40 years old. Nowadays, the age level is lower. An individual enrolled in $\mathrm{PhD}$ studies can earn their degree at the tender age of 25 . From this it is clear that a university teacher can be an associate professor as soon as at the age of 35 . According to formal criteria, such quick advancement is possible.

Concerning the age of earning a $\mathrm{PhD}$, the study participants can be divided into two groups:

- Those who earned a $\mathrm{PhD}$ before the age 30 .

- Those who earned a PhD at the age of 35 or later.

The first group is well represented by these quotes:

I have a lot of publications; however, I am unable to find a topic suitable for earning an associate professorship. A principal topic is required for it. But nobody will tell you which topic is principal. Therefore, many of us inspected the topics that had been defended. And the task is to detect why a topic was or was not successful. (M3)

When I was a student, I thought that if somebody was an associate professor or a full professor his books would stuff the shelves in a library. A professor is a man of reputation. Then I learned that this was not always true. One can earn these degrees quicker and in a smooth manner. (F6)

Participants of the second group are represented by the following quotes:

I am thinking of associate professorship but, to tell the truth, I hate it when a colleague boasts of this degree and I know how easily he earned it... and then I 


\section{Acta Technologica Dubnicae \\ volume 7,2017 , issue 1}

said to myself if an idiot like he did it why should I not do it myself. On the other hand, if such idiots pile up, then one can ask if having this degree would not assign you to a bad society... so everything needs time. (M2)

In the beginning, when I got the job at the university, I thought this was very easy. It simply goes by itself, quickly. These ideas were naïve. I did not know precisely how to earn an associate professorship. That is why I thought it was easy. I know now that it will not go rapidly, but the direction is clear. (F1)

I do not hurry to earn an associate professorship. I desire to be considered a reputable professional. One needs time to mature. (M1)

In the accounts of participants who belong to the first group, it appears that they found a research topic by searching the already-defended dissertations. This, however, is an obscure practice of someone who wishes solely to earn a higher degree. A candidate should be a specialist in a particular field and well known in the professional community for a contribution to the development of this field.

In the first group, academic career acceleration seemingly rests on finding ways to ease the promotion process, or putting it bluntly, to play the system. In addition, the first group's conceptualisation of an associate professor's responsibilities appears inaccurate, as witnessed by the following quote.

When I become an associate professor, I will not be burdened by trifling matters, I will have more time to conduct research, I will have more influence, and I will meet relevant people. I will have a higher position than I have now. Associate professorship will make it possible to reach things that are currently unreachable. (F1)

In the second group, participants were aware that personal maturity is a necessary characteristic of associate professorship. The two groups differed in considerations of what an associate professor should do. The participants conceptualised associate professorship chiefly in relation to research, advising and assisting others.

An individual becomes an associate professor if he/she can advise others, if the individual subordinates their own benefits to the benefits of others, if he/she has a strong will to develop professionalism and if others consider him/her an expert in a field. (M1)

Professional routes of the two groups are depicted in Table 1: 
Table 1

Professional routes of the two groups are depicted

First group = academic route No. $1 \quad$ Second group $=$ academic route No. 2

Rapid pace of PhD studies; usual

Slower pace of $\mathrm{PhD}$ studies, usual

duration of 3 years. duration of 5-7 years.

Age of completion, 25-27

Age of completion, $30+$

Naïve conceptualisation of $\mathrm{PhD}$ studies;

Strong motivation for research strong motivation for earning an projects. associate professorship.

Effort to ease the route to associate Higher self-demands. professorship.

A distinct characteristic of the first group is conformity. The individual has quickly adapted to the options available for career advancement. Individuals in the second group are less conforming; they have high self-esteem and high confidence in their abilities. They aim to build excellent reputations in their fields and try not to ease the route to an assistant professorship.

It is impossible to identify causality between the level of conformity of a student and the quality of the doctoral studies. This was neither the aim of the study, nor can it be supported by the research data. However, the possible existence of such causality might be worth future investigation.

\subsection{A Teacher and a Researcher}

In addition to describing their career advancement, the participants explained visions of their professional growth, or rather of work improvement at a university. In their accounts, they described themselves as teachers and as researchers.

The participants' views of their university positions were influenced by their university employment contracts and by several years of experience, both of which helped determine their next professional steps.

The participants identified easily with the role of a university teacher because they previously taught at primary or secondary schools, making the role of an educator familiar to them. They knew instructional principles and didactical rules. This explains why they enrolled in pedagogy rather than in other disciplines. But the participants admitted they needed improvement in teaching 


\section{Acta Technologica Dubnicae \\ volume 7, 2017, issue 1}

skills. They teach adults, which is much different from teaching children. The participants stressed that instructional practices and pedagogical philosophies keep evolving, which challenges them.

To grow professionally, the participants

a) studied professional literature.

I moved further and further to new teaching methods, I searched in books, method manuals, or foreign publications. I desired to give students a lot of knowledge. (F7)

b) attended courses and workshops.

I used to travel to attend workshops in Prague, then in Brno. They were excellent, I learned a lot and I used the gained knowledge in the classroom. (F6)

c) had discussions with colleagues.

It is important to meet people, discuss my opinions with a colleague. This increases the chances of enriching students. (M2)

The accounts of all participants expressed a desire to assist students in their learning, which agrees with the findings of G. S. A kerlind in her research conducted at an Australian university (2007). University teachers focused on building a better knowledge of their content areas, in order to become more familiar with what to teach. They also continually increased their understanding of what works and does not work for students, in order to become more effective in facilitating student learning.

The instructional content and structure are in the teacher's hands, but they are in part shaped by accreditation documents, which, however, provide only an interpretation framework for the curriculum. The participants expressed the need for practical teaching skills and the development of a repertoire of instructional strategies. They also found it important to detect which strategies work best in providing content to students. They also considered how to adopt the teaching content to a particular class, how to present a topic to students as efficiently as possible, how to motivate them for learning, how to assign tasks and how to assess them. These activities, of course, are only a part of a university teacher's work.

University teaching is an occupational position within which educational, scientific, research and developmental activities are required, the results of which are then passed along to students. The full list of these activities is long, and the study participants have not yet met many of them. However, during their academic career, they will come across new tasks, which will bring new challenges. 


\section{Acta Technologica Dubnicae \\ volume 7,2017 , issue 1}

According to the study participants, a university teacher accomplishes these tasks:

- delivers lectures, heads seminars and organizes workshops,

- provides consultations,

- supervises theses and dissertations,

- develops organisational plans,

- proposes projects,

- publishes textbooks and other learning materials,

- publishes studies,

- cooperates with partners in the field,

- searches for and analyses new knowledge in the field,

- performs administrative tasks.

Of course, the participants have a simplified view of university teacher responsibilities, which reflects their narrow experience. Note, for instance, that the list does not contain academic research, which the participants were reluctant to talk about it - either theirs or their colleagues'.

Research about becoming a professional researcher is rich and there is a wealth of research data on becoming a teacher. Åkerlind (2008) identified four stages in the development of a researcher:

1. Becoming confident as a researcher. This stage involves acquiring the skills required to do research successfully, such as learning how best to choose a research topic, to present conference papers and write-up results, to do literature searches, etc. It might also involve clarifying a future research direction.

2. Becoming recognised as a researcher. In contrast to the previous stage, which involves the development of an internal sense of competence and success, this stage includes external recognition of one's competence and success by other academics in one's field. This is marked by becoming part of a research community, building a reputation in the community and having one's ideas adopted and used by others.

3. Becoming a more productive researcher. This stage views development as a quantitative increase in a researcher's productivity, that is, conducting larger research projects, teaching more $\mathrm{PhD}$ students and postdocs, receiving more funding, and publishing more. This increase can involve the simple accumulation of research activity over time and/or an increase in the rate of productivity through improved efficiency and the beneficial impact of one area of activity on another.

4. Becoming a more sophisticated researcher. This stage extends from the quantitative changes described in the previous category, to include a focus on qualitative changes as part of researcher development. These qualitative 


\section{Acta Technologica Dubnicae \\ volume 7, 2017, issue 1}

changes involve developing greater sophistication in thinking, becoming more theoretically aware, increasing breadth of knowledge, developing a greater depth of understanding, becoming aware of wider perspectives, being able to resolve issues and having an enhanced capacity to do research.

The participants in this study belong to the first developmental stage, higher stages being far away from their present research competences. It should be noted, however, that Åkerlind's sample included postdocs, which were not present in my sample.

In many countries, academic support is offered to postdocs through a variety of projects. This is in contrast to the situation in the Czech Republic, where $\mathrm{PhD}$ graduates are not provided specific assistance to enhance their research capacity. They are expected to be fully-developed researchers upon taking a teaching position at a university.

The participants who took academic route No. 1, defined previously, were explicit in describing their problems with starting a research project.

I failed to start my research. I wish I could be involved in a project, or propose one of my own, but I cannot decide on the topic. I feel like I am an apprentice. (F4)

The participants have not yet reached the stage of a productive researcher. For them, independent research projects were faraway targets. But this might change in the future. Rather than concentrating their efforts on growing academically, they criticise the career rules and wait for external support.

I want someone to supervise me, but they expect publications from me in order to gain points for some evaluation. I wish someone would come to me and offer participation in a project someday. (F5)

The participants that follow academic route No. 2, who had a slower career pace, appeared to make an effort to build a positive reputation within the academic community.

I am happy if I do meaningful things - if the topic is interesting and I collaborate with reasonable people. I am happy if I can present my findings and they are accepted by the community and cited. (M2)

Quite recently I published a book, which made me very happy. I have received favourable references, which pleases me. This is how I build respect within the academic community. (F2) 


\section{Acta Technologica Dubnicae \\ volume 7, 2017, issue 1}

As noted, some of the participants feel a need for acceptance within the academic community. It is of value for them because it is in harmony with their view of their career growth. They also are aware of the importance of conducting research projects.

I like doing projects, but in the Czech Republic large projects, such as $G A \check{C}^{l}$, they are accessible only to the chosen ones. I do not know how the selection is being made, but in the list of approved projects, one can repeatedly see the same names. (M2)

I have no chance to analyse and evaluate the objectivity of the system of approval of GA ČR proposals. PhD graduates generally have an opportunity to apply for the so-called junior projects. Nevertheless, the criteria are strict, and only a small percentage of $\mathrm{PhD}$ graduates can meet them. One of the criteria is at least six months studying and teaching abroad.

One of the participants succeeded in gaining a GA ČR grant, and he finds it an excellent research experience.

I managed to receive a GA $\check{C} R$ grant. It was demanding but I am fond of research methodology. I had some knowledge of statistics, I read Kerlinger and such stuff but now I am excited about the qualitative route. Suddenly, I found out that figures must be verbally interpreted to express meaning, and if I want to get underneath, there is no other direction. (M1)

A novice researcher should start their career with small-size projects, and only then proceed to larger ones. The Ministry of Education of the Czech Republic offers grants to support so-called specific university research. Every university has its own grant rules. Many universities support IGA projects ${ }^{2}$, which are targeted to doctoral students and postdocs. Some faculties offer grants for university teachers in collaboration with graduate student programmes. With this, a teacher takes up a more demanding role, as he/she must be able to propose a team project in order to succeed.

One of the participants has had experience with IGA projects.

${ }^{1}$ GA ČR are research grants provided by the agency of the government of the Czech Republic.

${ }^{2}$ IGA are grants provided by some universities in the Czech Republic to support specific university research. It is funded by the Ministry of Education. 


\section{Acta Technologica Dubnicae \\ volume 7,2017 , issue 1}

Now we have an IGA and we enjoy it. We are four women in the team. The collaboration is interesting and we learn a lot. We discuss matters and discussion means collaboration. We find solutions about our topic. (F2)

A novice university teacher needs time to grow to be a researcher. Experience in research is needed. The faculties that hire young $\mathrm{PhD}$ graduates should create the right research conditions and emphasize the important role of research in academia. It should be the strategy of a university to support $\mathrm{PhD}$ graduates not only to become teachers but also researchers. ${ }^{3}$

\section{Conclusions}

The study described the professional and academic careers of the study participants from the completion of their master's studies to their work at a university. This study synthesizes these findings. The data and categories were merged to form concepts and relationships that constitute a theoretical model of occupational and academic careers, including career determinants.

The study participants had personal values that influenced their beliefs about attaining university employment. They desired to work in academia and therefore concentrated their efforts towards reaching this goal. On the route to the position of a university teacher, each participant had at their disposal a set of career options and a repertoire of possibilities that could be used to achieve personal satisfaction. Their decisions were influenced by a range of career possibilities and opportunities. These personal decisions and their key determinants were integrated into a model that is depicted in Figure 1.

\footnotetext{
${ }^{3}$ This is in contrast with most of the West European and North American universities that are either teaching universities or research universities.
} 


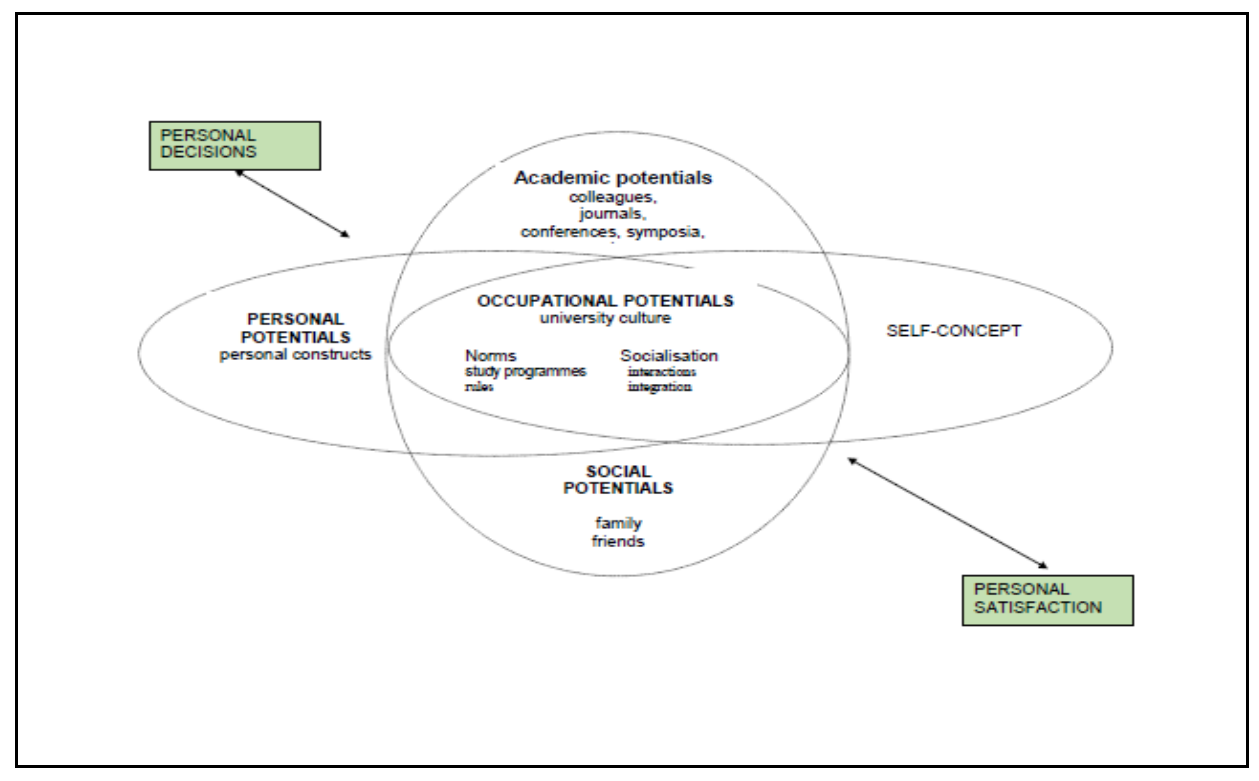

Figure 1. Personal decisions and career determinants of a university teacher.

Personal potentials are the abilities, values, and beliefs of an individual. They strongly affected the participants' behaviour and activities aimed at obtaining a job contract at a university. Personal potentials strongly interact with the family environment of an individual and with an individual's self-concept. A personal community consists of close relatives and friends. In general, a personal community motivates and stimulates an individual to utilize career possibilities and opportunities. To develop a sound self-concept and attain occupational success, a university teacher generally needs a satisfactory family milieu, and sympathy as well as a support from relatives and friends. Such a support was reported by study participants to be a strong emotional stimulus, especially if accompanied by financial and material aids.

A teacher's job at a university requires much understanding and extensive support from the immediate environment. The participants reported that family and friends had affirmed for them that they belong at a university and deserve a respected position in the academic community.

Occupational potentials are conditions of the university milieu. On the one hand, a university introduces norms and rules that regulate the employees' work. On the other hand, a university enables interactions among colleagues and students who constitute the academic community. A university needs to develop a culture 


\section{Acta Technologica Dubnicae \\ volume 7, 2017, issue 1}

that generates a teacher's personal satisfaction and motivation for high achievements.

The core component of academic potentials is an academic community, which is constituted by colleagues at a home university. A university teacher is gradually integrated also into a broader academic community, represented by partners from other universities. A teacher's scholarly reputation is gained by publishing quality research papers and monographs but also in face-to-face contacts in seminars, conferences and symposia. Experiences and knowledge exchange, both in domestic and international scientific events, shape a teacher's academic self-concept.

Over time, career possibilities and opportunities change. In order to make efficient career decisions, a university teacher assesses them. The interaction of decisions with career possibilities and opportunities has a significant influence upon the sequence of a teacher's career stages.

\section{References}

Akerlind, G. S. (2003). Growing and developing as a university teacher variation in meaning. Studies in Higher Education, 28(4), 375-390.

Akerlind, G. S. (2007). Constraints on academics' potential for developing as a teacher. Studies in Higher Education, 32(1), 21-37.

Akerlind, G. S. (2008). Growing and developing as a university researcher. Higher Education, 55(2), 241-254.

Davis, G. (2013). Advising and Supervising Doctoral Students: Lessons I Have Learned. University of Minnesota. Retrieved from http://misrc/umn.edu/ workingpapers/fullpapers/2004/0412_052404.pdf.

Gardner, S. K. (2007). „I heard it through the grapevine": Doctoral student socialization in chemistry and history. Higher Education, 54(5), 723-740.

Jaraim, D., \& Kahl, D. H. (2012). Navigating the doctoral experience: The role of social support in successful degree completion. International Journal of Doctoral Studies, 7, 311-329.

Mareš, J. (2013). Neviditelná skupina aneb co s postdoktorandy? Pedagogická orientace, 23(1), 5-26.

McAlpine, L., Jazvac-Martek, M., \& Hopwood, N. (2009). Doctoral student experience in Education: Activities and difficulties influencing identity development. International Journal for Researcher Development, 1(1), 97 109.

Melin, G. (2005). The dark side of mobility: negative experiences of doing a postdoc period abroad. Research Evaluation, 14(3), 229-237. 


\section{Acta Technologica Dubnicae \\ volume 7,2017 , issue 1}

Milkovich, G. T., \& Boudreau, J. W. (1993). Řizení lidských zdrojů. Praha: Grada.

Neusar, A., Charvát, M., Dolejš, M., Smetáčková, I., Kolařík, M., Kundrát, J., \& Szarzyńska M. (2012). PhD existence voboru psychologie v České republice a na Slovensku. Olomouc: Filozofická fakulta Univerzity Palackého.

Šed’ová, K., Švaříček, R., Sedláčková, J., Čejková, I., Šmardová, A., Novotný, P., \& Zounek, J. (2016). Pojetí výuky a profesní identita začínajících vysokoškolských učitelů. Studia paedagogica, 21(1), 9-34.

Turner, G., \& McAlpine, L. (2011). Doctoral experience as researcher preparation: activities, passion, status. International Journal for Researcher Development, 2(1), 46-60.

Vekkaila, J., Pyhältö, K., \& Lonka, K. (2013). Experiences of disengagement A study of doctoral students in the behavioral sciences. International Journal of Doctoral Studies, 8, 61-81.

Weisgram, E. E., Bigler, R. S., \& Liben, L. S. (2010). Gender, values, and occupational interest among, children, adolescents and adults. Child Development, 81(3), 770-796. 